Research Paper

\title{
Efficacy of Palonosetron-Dexamethasone Combination Versus Palonosetron Alone for Preventing Nausea and Vomiting Related to Opioid-Based Analgesia: A Prospective, Randomized, Double-blind Trial
}

\author{
Eunah Cho',2, Do-Hyeong Kim³,4, Seokyung Shin'3,4, Seung Hyun Kim³, Young Jun Oh3,4, Yong Seon \\ $\mathrm{Choi}^{3,4}$
}

1. Department of Anesthesiology and Pain Medicine, Kangbuk Samsung Hospital, Sungkyunkwan University School of Medicine, Seoul, Korea

2. Department of Anesthesiology and Pain Medicine, College of Medicine, Kangwon National University, Chuncheon, Gangwon, Republic of Korea

3. Department of Anesthesiology and Pain Medicine, Severance Hospital, Yonsei University College of Medicine, Seoul, Korea

4. Anesthesia and Pain Research Institute, Yonsei University College of Medicine, Seoul, Korea

$\square$ Corresponding author: Yong Seon Choi, Department of Anesthesiology and Pain Medicine, Severance Hospital, Yonsei University College of Medicine, 50-1 Yonsei-ro, Seodaemun-gu, Seoul 03722, Korea. Tel: 82-2-2228-2412; Fax: 82-2-2227-7897; Email: yschoi@yuhs.ac

(C) Ivyspring International Publisher. This is an open access article distributed under the terms of the Creative Commons Attribution (CC BY-NC) license (https://creativecommons.org/licenses/by-nc/4.0/). See http://ivyspring.com/terms for full terms and conditions.

Received: 2017.12.06; Accepted: 2018.05.31; Published: 2018.06.13

\begin{abstract}
Background: The efficacy of dexamethasone plus palonosetron for postoperative nausea and vomiting (PONV) prophylaxis is not firmly established. This randomized, double-blind, controlled study evaluated whether the combination was superior to palonosetron alone in preventing PONV in patients receiving intravenous patient-controlled analgesia (IV-PCA) after upper extremity surgery.

Methods: A total of 202 patients undergoing upper extremity surgery were randomly assigned to group $\mathrm{P}$ (palonosetron alone) or group PD (palonosetron plus dexamethasone). Group P patients received palonosetron $0.075 \mathrm{mg}$ and normal saline $1.6 \mathrm{~mL}$; group PD patients received palonosetron $0.075 \mathrm{mg}$ and dexamethasone $8 \mathrm{mg}$. In both groups, palonosetron was added to the IV-PCA opioid infusion, which was continued for $48 \mathrm{~h}$ postoperatively. Incidence and severity of nausea, incidence of vomiting, rescue antiemetic requirements, pain intensity, and rescue analgesic requirements were evaluated for $72 \mathrm{~h}$ postoperatively. Quality of recovery was assessed using the quality of recovery-15 (QoR-15) questionnaire.

Results: The incidence of PONV was significantly lower in group PD than in group $\mathrm{P}$ at $0-48 \mathrm{~h}$ postoperatively $(61.5 \%$ vs $77.1 \%$; $\mathrm{p}=0.019)$. Severity of nausea at $0-6 \mathrm{~h}$ postoperatively was significantly less in group PD compared with group $P$ (none/mild/moderate/severe: 49/22/15/10 vs. 36/16/25/19, $p=$ 0.008). The incidence of vomiting and rescue antiemetic requirements were similar between groups. Pain intensity was significantly less in group PD than in group $\mathrm{P}$ at $0-48 \mathrm{~h}$ and $48-72 \mathrm{~h}$ postoperatively. Global QoR-15 was similar $24 \mathrm{~h}$ postoperatively between groups.

Conclusions: Dexamethasone-palonosetron combination therapy reduced PONV incidence and postoperative pain in patients receiving opioid-based analgesia after upper extremity surgery.
\end{abstract}

Key words: Dexamethasone, Palonosetron, Postoperative nausea and vomiting

\section{Background}

Postoperative nausea and vomiting (PONV) is one of the most common and distressing complications after surgery under general anesthesia. PONV may cause dehydration, electrolyte imbalance, aspiration of gastric contents, would dehiscence, bleeding, and delayed hospital discharge [1]. Despite the development of new antiemetics, the incidence of PONV still ranges from $10 \%$ to $80 \%$, depending on the presence of risk factors [2]. Factors associated with an increased risk of PONV include female sex, 
nonsmoking, postoperative opioid use, and history of motion sickness or PONV [2]. Opioid-based intravenous patient-controlled analgesia (IV-PCA), which is widely used for postoperative pain control, is associated with a high incidence of PONV [3]. Accordingly, multimodal strategies have been advocated to reduce the incidence of PONV in high-risk patients, including risk stratification and modification, and combination therapy of antiemetics with different sites of action [4].

5-hydroxytryptamine $3 \quad\left(5-\mathrm{HT}_{3}\right) \quad$ receptor antagonists are widely used for preventing PONV. They selectively bind to $5-\mathrm{HT}_{3}$ receptors in chemoreceptors within the brain and visceral vagal afferents [5]. Palonosetron, a second-generation 5- $\mathrm{HT}_{3}$ receptor antagonist, has a higher affinity for $5-\mathrm{HT}_{3}$ receptors and longer half-life $(>40 \mathrm{~h})$ than other $5-\mathrm{HT}_{3}$ antagonists because of its unique structure [6, 7]. Glucocorticoids exert antiemetic properties by antagonizing prostaglandins or releasing endorphins $[8,9]$. They can also potentiate other antiemetics by sensitizing pharmacologic receptors. Given these pharmacologic profiles, combining palonosetron and dexamethasone provides better prevention against chemotherapy-induced nausea and vomiting than palonosetron alone [10]. However, the few trials evaluating palonosetron-dexamethasone combination therapy for PONV prophylaxis produced conflicting results [11-13]. The discrepancies may be attributable to different observation periods and relatively small sample sizes, which increase the influence of interindividual pharmacokinetic and pharmacodynamic differences.

Palonosetron-dexamethasone combination therapy has not been heretofore compared to palonosetron monotherapy for preventing PONV related to opioid-based IV-PCA. Therefore, we conducted a prospective, randomized, double-blind study to evaluate whether combining the combination would be superior to palonosetron alone for preventing PONV in patients receiving IV-PCA opioids after upper extremity surgery.

\section{Methods}

\section{Study design and patient selection}

This randomized controlled trial was approved by the institutional ethics review committee of Severance Hospital, Korea (No.4-2015-0232) and registered at ClinicalTrials.gov (NCT02744508). A total of 202 patients were enrolled in this study between July 2015 and March 2017 at Severance Hospital. Patient inclusion criteria were as follows: age 20-65 years, undergoing elective upper extremity surgery under general anesthesia, American Society of Anesthesiologists' physical status class I-II, and use of IV-PCA for postoperative analgesia. Patients were excluded if they had one or more of the following: use of antiemetic medication within $24 \mathrm{~h}$ of surgery, glucocorticoids within $24 \mathrm{~h}$ before or after surgery, chronic opioid use, presence of renal dysfunction (serum creatinine $>1.6 \mathrm{mg} / \mathrm{dL}$ ) or hepatic insufficiency (liver enzymes more than twice the upper limit of normal), allergy to $5-\mathrm{HT}_{3}$ receptor antagonists, obesity (body mass index $\geq 35 \mathrm{~kg} / \mathrm{m}^{2}$ ), pregnant, and borderline or definite QTc prolongation (>430 ms for males, $>450 \mathrm{~ms}$ for females). Written informed consent was obtained from all patients before enrollment.

The day before surgery, the principal investigator (Y.S.C.) randomly allocated the patients to either the palonosetron group (group $\mathrm{P}$ ) or palonosetron plus dexamethasone group (group PD), using computer-generated random-number codes. The other investigators, anesthesiologists responsible for the patients' care, surgeons, and patients were blinded to the group assignments during the entire study period.

\section{Perioperative management}

No premedication was administered. On arrival in the operating room, standard anesthetic monitors were applied. Anesthesia was induced with remifentanil $1.0 \mu \mathrm{g} / \mathrm{kg}$ and propofol $1.5 \mathrm{mg} / \mathrm{kg}$, and orotracheal intubation was facilitated with rocuronium $0.6 \mathrm{mg} / \mathrm{kg}$. According to the allocated group, dexamethasone $8 \mathrm{mg}$ or normal saline $1.6 \mathrm{~mL}$ was injected immediately after induction of anesthesia. The study drugs were prepared in identical syringes by nurses not involved in the study. Anesthesia was maintained with $0.1-0.2 \mu \mathrm{g} / \mathrm{kg} / \mathrm{min}$ remifentanil intravenous (IV) infusion and 1.5\%-2\% sevoflurane in $50 \%$ oxygen/air. Approximately 30 min before the end of surgery, all patients received IV palonosetron $0.075 \mathrm{mg}$. Fifteen minutes before the end of surgery, the remifentanil infusion was stopped, and IV fentanyl $1 \mu \mathrm{g} / \mathrm{kg}$ was administered to reduce postoperative pain. Concurrently, IV-PCA was commenced, which consisted of fentanyl $20 \mu \mathrm{g} / \mathrm{kg}$ plus palonosetron $0.075 \mathrm{mg}$ (total volume including saline: $100 \mathrm{~mL}$ ), delivered as a $2 \mathrm{~mL} / \mathrm{h}$ background infusion and $0.5-\mathrm{ml}$ demand doses with a 15-min lockout period. This was continued for $48 \mathrm{~h}$ after surgery. Upon completion of surgery, neuromuscular blockade was antagonized with glycopyrrolate $(0.2$ $\mathrm{mg})$ and neostigmine $(50 \mu \mathrm{g} / \mathrm{kg})$.

\section{Assessments}

Primary study endpoint was to compare the overall incidence of PONV between two groups for the first $48 \mathrm{~h}$ after surgery during hospitalization. Secondary endpoints were the incidence of 
postdischarge nausea and vomiting (PDNV), incidence and severity of nausea, incidence of vomiting, rescue antiemetic requirements, pain intensity, and rescue analgesic requirements. Outcome variables were assessed at 0-6, 6-24, 24-48, and $48-72 \mathrm{~h}$ postoperatively. Nausea intensity was graded on an 11-point verbal numeric rating scale (VNRS), from $0=$ no nausea to $10=$ worst possible nausea. Nausea severity was classified according to VNRS scores: mild (1-3), moderate (4-6), and severe (7-10). IV metoclopramide $10 \mathrm{mg}$ was administered when the nausea VNRS was $\geq 4$ or the patient requested an antiemetic. In case of severe persistent nausea after administering metoclopramide, or by patient request, IV-PCA was stopped for $2 \mathrm{~h}$. Vomiting was defined as forceful expulsion of gastric contents (true vomiting) or vomiting-like action without gastric contents (retching). Pain was evaluated using an 11-point VNRS, from $0=$ no pain to $10=$ worst imaginable pain. IV tramadol $50 \mathrm{mg}$ was given for a pain VNRS $\geq 4$ or upon patient request. The quality of recovery (QoR)-15 questionnaire was used to evaluate recovery from anesthesia [14]. The QoR-15 was administered the day before surgery and $24 \mathrm{~h}$ postoperatively. If patients were discharged home before $72 \mathrm{~h}$ postoperatively, we contacted them by telephone to collect data regarding PDNV. Pain medications at discharge included oral tramadol 37.5 $\mathrm{mg}$ and acetaminophen $325 \mathrm{mg}$ twice daily for 5 days.

\section{Statistical analysis}

Based on the $67 \%$ incidence of PONV with palonosetron reported previously [3], we determined that 96 patients in each group would be necessary to detect a 20\% decrease in the incidence of PONV with a power of $80 \%$ and a type I error of 0.05 . To account for a potential 5\% dropout rate, we enrolled 202 patients. Data are presented as mean \pm standard deviation or median (interquartile range) for continuous variables or number (percentage) for categorical variables. Data were analyzed with the independent t-test or Mann-Whitney $U$ test for continuous variables and chi-square or Fisher's exact test for categorical variables. P-values $<0.05$ were considered statistically significant. Statistical analyses were performed with SPSS 23.0 (SPSS Inc., Chicago, IL, USA).

\section{Results}

Among the 254 patients assessed for eligibility, 202 were enrolled in this study. After allocation, eight patients refused IV-PCA on the day of surgery or withdrew their consent; during follow-up, IV-PCA pumps were discontinued in two patients in group $\mathrm{P}$ following attempt of temporary interruption; data from the 192 remaining patients were finally analyzed (Fig. 1). Patient characteristics (including Apfel's risk scores [2]), and duration of surgery and anesthesia were comparable between two groups (Table 1).

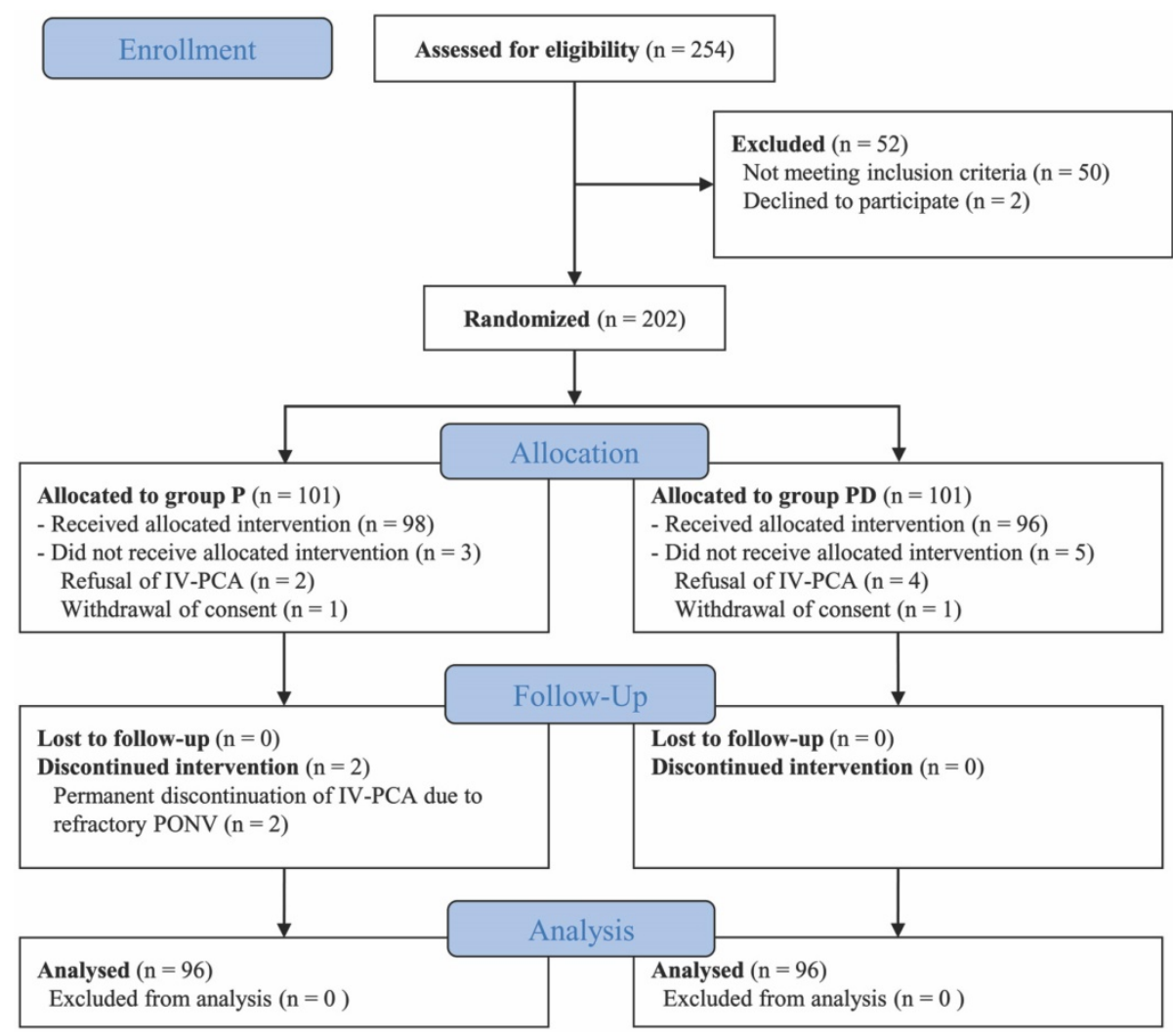

Figure 1. Flow diagram of the study 
Table 1. Patient characteristics and duration of surgery and anesthesia

\begin{tabular}{|c|c|c|c|}
\hline & Group P $(n=96)$ & Group PD (n = 96) & $p$ value \\
\hline Age (y) & $45.5 \pm 13.7$ & $44.1 \pm 13.9$ & 0.491 \\
\hline Sex (male/female) & $51 / 45$ & $45 / 51$ & 0.386 \\
\hline Height $(\mathrm{cm})$ & $166.1 \pm 10.1$ & $164.9 \pm 9.32$ & 0.418 \\
\hline Weight (kg) & $66.5 \pm 12.3$ & $65.0 \pm \pm 13.3$ & 0.438 \\
\hline Body mass index $\left(\mathrm{kg} / \mathrm{m}^{2}\right)$ & $24.0 \pm 3.1$ & $23.8 \pm 3.6$ & 0.703 \\
\hline Apfel risk score * & & & 0.779 \\
\hline 1 & $21(21.9 \%)$ & $20(20.8 \%)$ & \\
\hline 2 & $44(45.8 \%)$ & $43(44.8 \%)$ & \\
\hline 3 & $29(30.2 \%)$ & $31(32.3 \%)$ & \\
\hline 4 & $2(2.1 \%)$ & $2(2.1 \%)$ & \\
\hline Duration of surgery (min) & $80.8 \pm 47.8$ & $76.8 \pm 40.1$ & 0.533 \\
\hline Duration of anesthesia (min) & $123.4 \pm 53.3$ & $118.4 \pm 49.6$ & 0.500 \\
\hline Type of surgery & & & 0.604 \\
\hline Bone surgery & $52(54.2 \%)$ & $43(44.8 \%)$ & \\
\hline Soft tissue surgery & $26(27.1 \%)$ & $30(31.3 \%)$ & \\
\hline Arthroplasty & $3(3.1 \%)$ & $3(3.1 \%)$ & \\
\hline Arthroscopy & $15(15.6 \%)$ & $20(20.8 \%)$ & \\
\hline Intraoperative crystalloid (mL) & $455 \pm 193$ & $416 \pm 209$ & 0.183 \\
\hline \multicolumn{4}{|c|}{$\begin{array}{l}\text { Data are presented as mean } \pm \text { standard deviation, number of patients, or number of } \\
\text { patients (percentage). }\end{array}$} \\
\hline \multicolumn{4}{|c|}{$\begin{array}{l}\text { Group P received palonosetron; Group PD received palonosetron plus } \\
\text { dexamethasone. }\end{array}$} \\
\hline * Based on the reference [2]. & & & \\
\hline
\end{tabular}

Table 2. Incidence of nausea, vomiting, and rescue antiemetic requirements during hospital stay

\begin{tabular}{lccc}
\hline & Group P $(\mathrm{n}=96)$ & Group PD $(\mathrm{n}=96)$ & $p$ value \\
\hline 0-6 h after surgery & $60(62.5 \%)$ & $47(49.0 \%)$ & 0.059 \\
Nausea & $10(10.4 \%)$ & $8(8.3 \%)$ & 0.620 \\
Vomiting & $61(63.5 \%)$ & $47(49.0 \%)$ & $0.042^{*}$ \\
PONV & $19(19.8 \%)$ & $20(20.8 \%)$ & 0.858 \\
Rescue antiemetics & & & \\
6-24 h after surgery & $62(64.6 \%)$ & $52(54.2 \%)$ & 0.142 \\
Nausea & $11(11.5 \%)$ & $11(11.5 \%)$ & 1.000 \\
Vomiting & $62(64.6 \%)$ & $52(54.2 \%)$ & 0.142 \\
PONV & $6(6.3 \%)$ & $11(11.5 \%)$ & 0.204 \\
Rescue antiemetics & & $37(38.5 \%)$ & 0.463 \\
24-48 h after surgery & $42(43.8 \%)$ & $5(5.2 \%)$ & 0.721 \\
Nausea & $3(3.1 \%)$ & $37(38.5 \%)$ & 0.463 \\
Vomiting & $42(43.8 \%)$ & $1(1.0 \%)$ & 1.000 \\
PONV & $2(2.1 \%)$ & & \\
Rescue antiemetics & & $59(61.5 \%)$ & $0.019^{*}$ \\
0-48 h after surgery & $74(77.1 \%)$ & $16(16.7 \%)$ & 0.575 \\
Nausea & $19(19.8 \%)$ & $59(61.5 \%)$ & $0.019^{*}$ \\
Vomiting & $74(77.1 \%)$ & $25(26.0 \%)$ & 0.869 \\
PONV & $24(25.0 \%)$ & & \\
Rescue antiemetics & & & \\
Data are presented as number of patients (percentage). & \\
PONV, postoperative nausea and vomiting & & \\
Group P received palonosetron; Group PD received palonosetron plus \\
dexamethasone.
\end{tabular}

Table 3. Incidence of nausea and vomiting and intensity of pain after discharge to home

\begin{tabular}{|c|c|c|c|}
\hline & Group P $(\mathrm{n}=84)$ & Group PD (n = 87) & $p$ value \\
\hline \multicolumn{4}{|l|}{$48-72 \mathrm{~h}$ after surgery } \\
\hline Nausea & $33(39.3 \%)$ & $28(32.3 \%)$ & 0.332 \\
\hline Vomiting & $0(0.0 \%)$ & $2(2.3 \%)$ & 0.497 \\
\hline PDNV & $33(39.3 \%)$ & $28(32.2 \%)$ & 0.332 \\
\hline Median VNRS pain scores & $3.0(1.1-4.0)$ & $1.0(0.0-3.0)$ & $0.001^{*}$ \\
\hline \multicolumn{4}{|c|}{$\begin{array}{l}\text { Data are presented as number of patients (percentage) or median (interquartile } \\
\text { range). }\end{array}$} \\
\hline \multicolumn{4}{|c|}{$\begin{array}{l}P D N V \text {, postdischarge nausea and vomiting, VNRS, verbal numeric rating scale } \\
\text { Group P received palonosetron; Group PD received palonosetron plus } \\
\text { dexamethasone. }\end{array}$} \\
\hline
\end{tabular}

Table 4. Pain intensity and rescue analgesics during hospital stay

\begin{tabular}{|c|c|c|c|}
\hline & $\begin{array}{l}\text { Group P }(\mathrm{n}= \\
96)\end{array}$ & Group PD $(n=96)$ & $p$ value \\
\hline \multicolumn{4}{|c|}{ Median VNRS pain scores } \\
\hline $0-6 \mathrm{~h}$ after surgery & $5.0(4.0-7.0)$ & $4.0(3.0-6.0)$ & $<0.001^{*}$ \\
\hline $6-24 \mathrm{~h}$ after surgery & $5.0(3.0-6.0)$ & $3.0(1.0-4.0)$ & $<0.001^{*}$ \\
\hline $24-48 \mathrm{~h}$ after surgery & $3.0(2.0-5.0)$ & $2.0(1.0-4.0)$ & $0.001^{*}$ \\
\hline \multicolumn{4}{|c|}{ Patients requiring rescue analgesics } \\
\hline $0-6 \mathrm{~h}$ after surgery & $40(41.7 \%)$ & $28(29.2 \%)$ & 0.070 \\
\hline $6-24 \mathrm{~h}$ after surgery & $16(16.7 \%)$ & $15(15.6 \%)$ & 0.845 \\
\hline $24-48 \mathrm{~h}$ after surgery & $2(2.1 \%)$ & $3(3.1 \%)$ & 1.000 \\
\hline \multicolumn{4}{|c|}{ Total amount of tramadol (mg) } \\
\hline $0-48 \mathrm{~h}$ after surgery & $30.0 \pm 36.4$ & $26.8 \pm 49.4$ & 0.618 \\
\hline \multicolumn{4}{|c|}{$\begin{array}{l}\text { Data are presented as median (interquartile range), number of patients } \\
\text { (percentage), and mean } \pm \text { standard deviation. }\end{array}$} \\
\hline \multicolumn{4}{|c|}{$\begin{array}{l}\text { VNRS, verbal numeric rating scale } \\
\text { Group P received palonosetron; Group PD received palonosetron plus } \\
\text { dexamethasone. }\end{array}$} \\
\hline
\end{tabular}

The incidence of PONV was significantly lower in group PD than in group P at $0-6 \mathrm{~h}(49.0 \%$ vs $63.5 \%$, $p<0.05)$ and $0-48$ h postoperatively $(61.5 \%$ vs $77.1 \%, p$ $<0.05)$, but not at $6-24 \mathrm{~h}(54.2 \%$ vs $64.6 \%)$ and $24-48 \mathrm{~h}$ (38.5\% vs $43.8 \%$ ) (Table 2). Among the 192 patients, 171 were discharged around $48 \mathrm{~h}$ postoperatively and were interviewed by telephone the next day; 21 were discharged $72 \mathrm{~h}$ after surgery. The incidence of PDNV was similar between groups at 48-72 $h$ postoperatively (Table 3 ). The incidence of nausea was lower in group PD than in group $\mathrm{P}$ at $0-48 \mathrm{~h}$ postoperatively $(61.5 \%$ vs $77.1 \%, p=0.019)$, but not at 48-72 $\mathrm{h}$. The incidence of vomiting and rescue antiemetic requirements were similar between groups throughout the observation period. Nausea severity was graded as none, mild, moderate, and severe in 49 , 22,15 , and 10 patients, respectively, in group PD; and as $36,16,25$, and 19 patients, respectively, in group $\mathrm{P}$ $(p=0.008)$ (Fig. 2). Nausea severity was similar between groups during at 6-24 h, 24-48 h, and 48-72 h postoperatively. The need to temporarily discontinue IV-PCA due to PONV was similar between groups (four patients in group P vs. five in group PD).

Pain intensity (VNRS scores) was significantly lower in group PD than in group P at 0-48 $\mathrm{h}$ and $48-72$ $\mathrm{h}$ postoperatively (Table 4). The number of patients requiring rescue analgesics and total amount of rescue analgesic (tramadol) was similar between groups at 0-48 h (Table 4).

Preoperative global QoR-15 scores were similar between groups (group P, 132.0 \pm 18.7 vs group PD, $134.4 \pm 15.8, p=0.345)$. Postoperative global QoR-15 scores were comparable between groups, but four questions were significantly higher in group PD than in group P: "getting support from hospital doctors and nurses" (9.4 \pm 1.5 vs. $8.4 \pm 2.5, p=0.001)$; "having a feeling of general well-being" $(8.5 \pm 2.0$ vs. $7.7 \pm 2.9, p=$ $0.033)$; "moderate pain" (5.9 \pm 3.2 vs. $4.9 \pm 2.9, p=0.040$ ); and "severe pain" (7.6 \pm 3.1 vs. $6.3 \pm 3.1$ vs $p=0.007)$ (Table 5). 


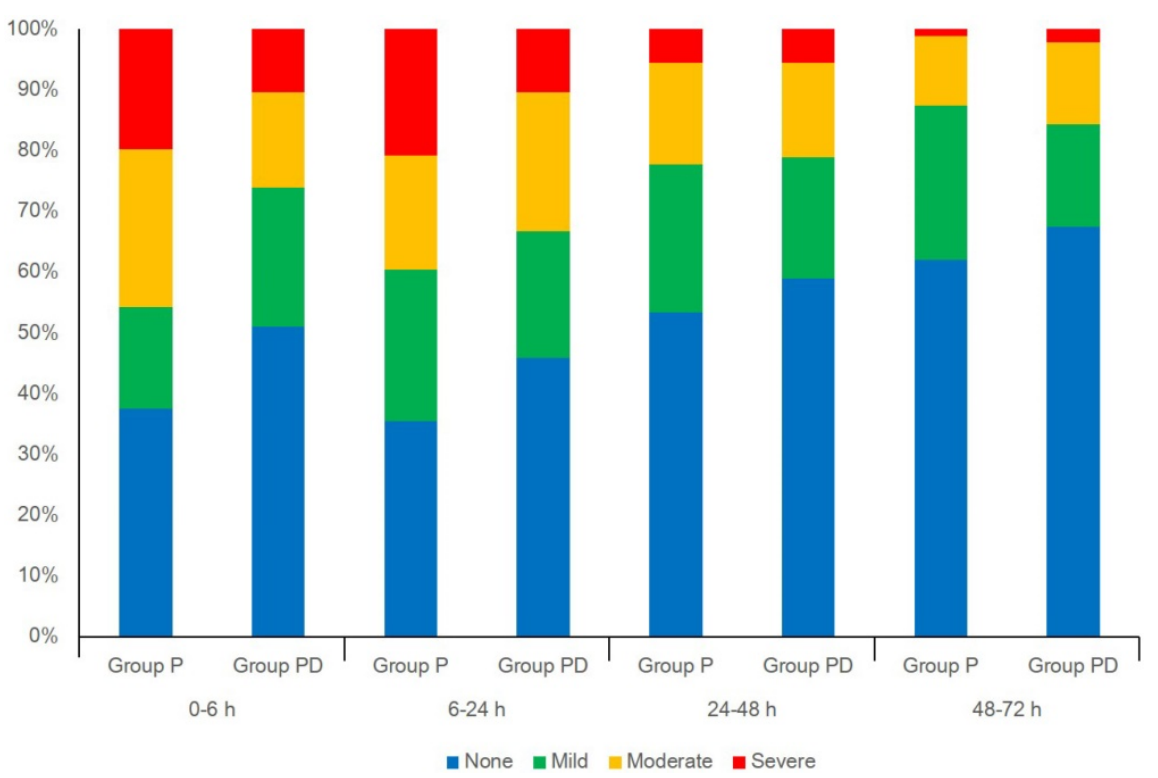

Figure 2. Distribution (percentage) of nausea severity according to a four-point rating scale (none, mild, moderate, or severe).

Table 5. Postoperative quality of recovery (QoR)-15 scores

\begin{tabular}{llll}
\hline QoR-15 Item & \multicolumn{2}{l}{ Group P $\left(\mathrm{n}=\begin{array}{l}\text { Group PD }(\mathrm{n}= \\
\text { 96 value }\end{array}\right.$} \\
\hline 1. Able to breathe easy & $9.4 \pm 1.4$ & $9.3 \pm 1.2$ & 0.621 \\
2. Been able to enjoy food & $6.8 \pm 3.8$ & $7.3 \pm 3.3$ & 0.383 \\
3. Feeling rested & $6.3 \pm 3.2$ & $6.5 \pm 2.7$ & 0.698 \\
4. Have had a good sleep & $6.7 \pm 3.4$ & $6.1 \pm 3.3$ & 0.234 \\
5. Able to look after personal toilet and & $6.6 \pm 3.3$ & $6.7 \pm 3.3$ & 0.780 \\
hygiene unaided & & & \\
6. Able to communicate with family or & $9.3 \pm 1.9$ & $9.7 \pm 1.0$ & 0.127 \\
friends & & & \\
7. Getting support from hospital doctors & $8.4 \pm 2.5$ & $9.4 \pm 1.5$ & $0.001^{*}$ \\
and nurses & & & \\
8. Able to return to work or usual home & $7.0 \pm 3.6$ & $6.4 \pm 3.4$ & 0.252 \\
activities & & & \\
9. Feeling comfortable and in control & $8.5 \pm 2.4$ & $8.5 \pm 2.1$ & 0.949 \\
10. Having a feeling of general well-being & $7.7 \pm 2.9$ & $8.5 \pm 2.0$ & $0.033^{*}$ \\
11. Moderate pain & $4.9 \pm 2.9$ & $5.9 \pm 3.2$ & $0.040^{*}$ \\
12. Severe pain & $6.3 \pm 3.1$ & $7.6 \pm 3.1$ & $0.007^{*}$ \\
13. Nausea or vomiting & $6.8 \pm 3.2$ & $7.0 \pm 3.5$ & 0.670 \\
14. Feeling worried or anxious & $8.2 \pm 2.7$ & $8.1 \pm 2.7$ & 0.894 \\
15. Feeling sad or depressed & $8.3 \pm 3.0$ & $8.6 \pm 2.7$ & 0.467 \\
Total & $111.5 \pm 27.3$ & $115.6 \pm 24.3$ & 0.298 \\
\hline
\end{tabular}

Data are presented as mean \pm standard deviation. $Q o R$, quality of recovery.

In QoR-15, the first ten questionnaires showed ratings from 0 (none of the time) to 10 (all of the time) and the last five questionnaires reversely showed ratings from 10 (all of the time) to 0 (none of the time).

Group P received palonosetron; Group PD received palonosetron plus dexamethasone.

* $p<0.05$

The most common 5- $\mathrm{HT}_{3}$ antagonist-related adverse effects were dizziness (group P, 20; PD, 17) and headache (group P, 19; PD, 13); the incidence of these effects was similar between groups throughout the study. No patient developed delayed wound healing, infection, or glucose intolerance. The duration of postoperative hospital stay was similar in both groups.

\section{Discussion}

In this prospective, randomized, double-blind trial, we demonstrated that combining dexametha- sone $8 \mathrm{mg}$ with palonosetron $0.075 \mathrm{mg}$ was superior to palonosetron $0.075 \mathrm{mg}$ alone in reducing the incidence of PONV related to opioid-based IV-PCA during the first $48 \mathrm{~h}$ after upper extremity surgery. The combination also conferred superior analgesia, significantly reducing pain scores throughout the 72-h postoperative period. It likewise produced significant benefits for certain aspects of quality of recovery after surgery: better perception of receiving support from hospital personnel, better general well-being, and less pain.

The etiology of PONV is multifactorial, with several established risk factors that include female gender, non-smoker status, history of PONV or motion sickness, use of perioperative opioids, use of volatile anesthetics, duration of anesthesia, duration of surgery, and type of surgery [2]. Postoperative pain management using opioid-based IV-PCA often produces PONV, which is the most common reason for patient dissatisfaction with this analgesic strategy. Accordingly, when opioid-based IV-PCA is planned, clinicians often initiate prophylactic antiemetic treatment. Current PONV guidelines recommend combined antiemetic therapies targeting different receptors in patients with a moderate to high risk for PONV [4]. In this study, PONV risk factors were similar between groups; thus, the difference in incidence of PONV between groups is attributed to the additive or synergistic effect of adding dexamethasone to palonosetron.

Dexamethasone plus a $5-\mathrm{HT}_{3}$ receptor antagonist has been previously reported to reduce the incidence of PONV compared with $5-\mathrm{HT}_{3}$ receptor antagonist alone $[9,15]$. Although the precise mechanism of dexamethasone's antiemetic effect is unclear, leading 
theories include prostaglandin antagonism and endorphin release $[8,9]$. Furthermore, dexamethasone may inhibit the synthesis and release of 5-HT by depleting tryptophan (a 5-HT precursor) or it may prevent activation of 5-HT receptors in the gastrointestinal tract through its anti-inflammatory properties [16, 17]. Palonosetron exhibits allosteric interactions and triggers receptor internalization; this produces high receptor affinity, making palonosetron the most potent available $5-\mathrm{HT}_{3}$ antagonist, with a 40-h elimination half-life [6, 18]. A recent meta-analysis showed that palonosetron provided better prophylaxis of early $(0-6 \mathrm{~h})$ and late $(6-24 \mathrm{~h})$ postoperative nausea, as well as late (6-24 h) postoperative vomiting, compared with ondansetron [19]. In another meta-analysis, palonosetron was more effective in preventing postoperative vomiting than ramosetron during the delayed period (24-48 $\mathrm{h}$ ) and in females and after laparoscopic surgery [20]. This delayed period is especially important in patients receiving opioid-based IV-PCA because continuous infusion of opioids could cumulatively influence PONV in a dose-related [21]. Although we found that palonosetron-dexamethasone reduced the incidence of PONV and the incidence and severity of nausea during the 48-h postoperative period compared with palonosetron alone, it did not affect vomiting. As palonosetron has more antiemetic than antinauseant efficacy, the main effect of dexamethasone may have been preventing nausea [20, 22]. Furthermore, adding palonosetron to the IV-PCA in all patients potentially influenced our results. Contrary to our expectation, the palonosetron-dexamethasone combination did not reduce the incidence of PDNV at 48-72 h. Since the duration of single dexamethasone for prevention of PONV lasts for about 24 hours, the comparable incidence of PDNV at 48-72 h may be explained by prolonged $(>40 \mathrm{~h})$ duration of action of palonosetron itself [23]. Our overall incidence of PDNV was 36\%, which is similar to the incidence previously reported [24].

In this study, incidence of PONV at $0-24 \mathrm{~h}$ was still higher than that of previous studies $[12,13]$. The use of opioid-based IV-PCA might explain this result. In our study, all patients were at least with Apfel risk score 1 due to IV-PCA use, and more than half of them were with Apfel risk scores 2 and 3. High background infusion dosage of fentanyl $(0.4 \mu \mathrm{g} / \mathrm{kg} / \mathrm{h})$ of IV-PCA in our study might also increase the incidence of PONV [25]. Although there is no definite dose of opioid that increases the risk of PONV, it is known that a higher dose of opioid tends to increase the risk of PONV [21].

Only a few previous studies evaluated the dexamethasone-palonosetron combination for preventing PONV. Our results are consistent with those of a previous study comparing palonosetron $0.075 \mathrm{mg}$ plus dexamethasone $8 \mathrm{mg}$ with palonosetron alone, in which the complete response rate (no vomiting, no antiemetic rescue medications) and PONV were superior with combination therapy during $24 \mathrm{~h}$ postoperatively in 84 patients undergoing laparoscopic cholecystectomy [12]. In a study comparing palonosetron $0.075 \mathrm{mg}$ plus dexamethasone $8 \mathrm{mg}$ with palonosetron monotherapy in 118 patients undergoing outpatient laparoscopy, the incidence of PONV at $72 \mathrm{~h}$ was similar and relatively low (31\% and $32 \%$ ) in both groups [13]. In another study involving 84 females undergoing various types of surgery, the complete response rate and incidence of PONV were similar for palonosetron $0.075 \mathrm{mg}$ plus dexamethasone $4 \mathrm{mg}$ and palonosetron monotherapy [11]. However, this study used a suboptimal dexamethasone dose. Although dexamethasone $2.5-5 \mathrm{mg}$ is the minimum effective dose for PONV prophylaxis, current literature suggests that the optimal dose is $8 \mathrm{mg}[8,15]$.

In our study, administering dexamethasone 8 $\mathrm{mg}$ before surgical incision reduced pain scores during the $72-\mathrm{h}$ postoperative period. A recent meta-analysis showed that a single perioperative dose of dexamethasone (1.25-20 $\mathrm{mg})$ reduced postoperative pain, opioid consumption, and need for rescue analgesics, and prolonged the time to first analgesic dose [26]. The onset of action of dexamethasone is approximately $1-2 \mathrm{~h}$, representing the time for diffusion across cell membranes and alteration of gene transcription [27]. Thus, administering glucocorticoids approximately $1 \mathrm{~h}$ before surgical trauma may be important for minimizing pain and inflammation [8].

Generally, palonosetron is recommended to be administered at anesthetic induction due to its slow onset of action [4]. In our study, palonosetron was administered approximately $30 \mathrm{~min}$ before the end of surgery considering its time-to-peak concentration of 2-9 minutes to maximize the duration of palonosetron after surgery [28]. Thereby, the incidence of PONV in 0-6 h after surgery in the palonosetron group might be affected by the timing of palonosetron administration, even though it is administered at the same time point in both groups. However, previous studies have shown that palonosetron significantly reduces PONV, regardless of when it is administered [29, 30]. In addition, one study showed that there was no significant effect on prevention of PONV according to the timing of palonosetron administration [28]. Therefore, further research is required to investigate the proper timing of palonosetron for PONV prevention. 
The importance of evaluating recovery from the patients' perspective, considering their emotions or feelings, has been previously established [14, 31, 32]. QOR-15 evaluates postoperative recovery in multiple dimensions, including pain, physical comfort, physical independence, psychological support, and emotional state. It is valid, reliable, acceptable, and quickly completed [14]. In this study, patients receiving combination therapy scored higher for questions about pain and mental well-being. This is consistent with the results of a previous study showing that $8 \mathrm{mg}$ dexamethasone improved patient recovery and satisfaction [31]. Enhanced feelings of well-being and of being supported might be attributed to dexamethasone's effects on mood, which may be due to direct effects on the central nervous system or indirect anti-inflammatory effects [33]. Reducing nausea and improving pain likely also improved patient satisfaction and recovery.

There are a few limitations in our study. First, this study was done without the placebo for ethical reasons since we evaluated patients with a moderate to high risk for PONV. Second, most patients were discharged home around $48 \mathrm{~h}$, requiring assessment by telephone $48-72 \mathrm{~h}$ postoperatively. However, this allowed us to study the effects of prophylaxis in two settings: inpatients and post-discharge outpatients. Third, the consumption of IV-PCA used was not measured in this study. The lower incidence of PONV in group PD might be associated with less IV-PCA use, related to analgesic effect of dexamethasone. To delineate this possibility, bolus-only mode of IV-PCA might be more helpful.

\section{Conclusions}

The combination of dexamethasone and palonosetron was more effective than palonosetron alone in reducing the incidence of PONV in patients receiving opioid-based analgesia during the first $48 \mathrm{~h}$ after upper extremity surgery. The combination also reduced the intensity of postoperative pain and improved certain aspects of the quality of recovery.

\section{Abbreviations}

HT: Hydroxytryptamine; IV: Intravenous; PCA: Patient-controlled analgesia; PDNV: Postdischarge nausea and vomiting; PONV: Postoperative nausea and vomiting; QoR: Quality of recovery; VNRS: Verbal numeric rating scale.

\section{Availability of data and materials}

The datasets collected and/or analyzed during the current study are available from the corresponding author on reasonable request.

\section{Ethics approval and consent to participate}

This study was approved by the institutional ethics review committee of Severance Hospital, Korea (IRB No.4-2015-0232). All patients provided a written informed consent for study participation.

\section{Competing Interests}

The authors have declared that no competing interest exists.

\section{References}

1. Watcha MF, White PF. Postoperative nausea and vomiting. Its etiology, treatment, and prevention. Anesthesiology. 1992; 77: 162-84.

2. Apfel CC, Laara E, Koivuranta M, Greim CA, Roewer N. A simplified risk score for predicting postoperative nausea and vomiting: conclusions from cross-validations between two centers. Anesthesiology. 1999; 91: 693-700.

3. Roh GU, Yang SY, Shim JK, Kwak YL. Efficacy of palonosetron versus ramosetron on preventing opioid-based analgesia-related nausea and vomiting after lumbar spinal surgery: a prospective, randomized, and double-blind trial. Spine. 2014; 39: E543-9.

4. Gan TJ, Diemunsch P, Habib AS, Kovac A, Kranke P, Meyer TA, et al. Consensus guidelines for the management of postoperative nausea and vomiting. Anesthesia and analgesia. 2014; 118: 85-113.

5. Andrews PL. Physiology of nausea and vomiting. British journal of anaesthesia. 1992; 69: 2s-19s.

6. Chun HR, Jeon IS, Park SY, Lee SJ, Kang SH, Kim SI. Efficacy of palonosetron for the prevention of postoperative nausea and vomiting: a randomized, double-blinded, placebo-controlled trial. British journal of anaesthesia. 2014; 112: 485-90.

7. Candiotti KA, Kovac AL, Melson TI, Clerici G, Joo Gan T. A randomized, double-blind study to evaluate the efficacy and safety of three different doses of palonosetron versus placebo for preventing postoperative nausea and vomiting. Anesthesia and analgesia. 2008; 107: 445-51.

8. Holte $\mathrm{K}$, Kehlet $\mathrm{H}$. Perioperative single-dose glucocorticoid administration: pathophysiologic effects and clinical implications. Journal of the American College of Surgeons. 2002; 195: 694-712.

9. Henzi I, Walder B, Tramer MR. Dexamethasone for the prevention of postoperative nausea and vomiting: a quantitative systematic review. Anesthesia and analgesia. 2000; 90: 186-94

10. Hajdenberg J, Grote T, Yee L, Arevalo-Araujo R, Latimer LA. Infusion of palonosetron plus dexamethasone for the prevention of chemotherapy-induced nausea and vomiting. The journal of supportive oncology. 2006; 4: 467-71

11. Park JW, Jun JW, Lim YH, Lee SS, Yoo BH, Kim KM, et al. The comparative study to evaluate the effect of palonosetron monotherapy versus palonosetron with dexamethasone combination therapy for prevention of postoperative nausea and vomiting. Korean J Anesthesiol. 2012; 63: 334-9.

12. Bala I, Bharti N, Murugesan S, Gupta R. Comparison of palonosetron with palonosetron-dexamethasone combination for prevention of postoperative nausea and vomiting in patients undergoing laparoscopic cholecystectomy. Minerva anestesiologica. 2014; 80: 779-84.

13. Blitz JD, Haile M, Kline R, Franco L, Didehvar S, Pachter HL, et al. A randomized double blind study to evaluate efficacy of palonosetron with dexamethasone versus palonosetron alone for prevention of postoperative and postdischarge nausea and vomiting in subjects undergoing laparoscopic surgeries with high emetogenic risk. American journal of therapeutics. 2012; 19: 324-9.

14. Stark PA, Myles PS, Burke JA. Development and psychometric evaluation of a postoperative quality of recovery score: the QoR-15. Anesthesiology. 2013; 118: $1332-40$.

15. Awad K, Ahmed H, Abushouk AI, Al Nahrawi S, Elsherbeny MY, Mustafa $\mathrm{SM}$, et al. Dexamethasone combined with other antiemetics versus single antiemetics for prevention of postoperative nausea and vomiting after laparoscopic cholecystectomy: An updated systematic review and meta-analysis. International journal of surgery. 2016; 36: 152-63.

16. Young SN. Mechanism of decline in rat brain 5-hydroxytryptamine after induction of liver tryptophan pyrrolase by hydrocortisone: roles of tryptophan catabolism and kynurenine synthesis. British journal of pharmacology. 1981; 74: 695-700.

17. Fredrikson M, Hursti T, Furst CJ, Steineck G, Borjeson S, Wikblom M, et al. Nausea in cancer chemotherapy is inversely related to urinary cortisol excretion. British journal of cancer. 1992; 65: 779-80.

18. Yang LP, Scott LJ. Palonosetron: in the prevention of nausea and vomiting. Drugs. 2009; 69: 2257-78.

19. Xiong C, Liu G, Ma R, Xue J, Wu A. Efficacy of palonosetron for preventing postoperative nausea and vomiting: a systematic review and meta-analysis. Canadian journal of anaesthesia = Journal canadien d'anesthesie. 2015; 62: 1268-78. 
20. Kim MS, Park JH, Choi YS, Park SH, Shin S. Efficacy of Palonosetron vs. Ramosetron for the Prevention of Postoperative Nausea and Vomiting: A Meta-Analysis of Randomized Controlled Trials. Yonsei Med J. 2017; 58: 848-58.

21. Roberts GW, Bekker TB, Carlsen HH, Moffatt CH, Slattery PJ, McClure AF. Postoperative nausea and vomiting are strongly influenced by postoperative opioid use in a dose-related manner. Anesthesia and analgesia. 2005; 101: 1343-8.

22. Tramer MR. A rational approach to the control of postoperative nausea and vomiting: evidence from systematic reviews. Part II. Recommendations for prevention and treatment, and research agenda. Acta anaesthesiologica Scandinavica. 2001; 45: 14-9.

23. Wang JJ, Ho ST, Tzeng JI, Tang CS. The effect of timing of dexamethasone administration on its efficacy as a prophylactic antiemetic for postoperative nausea and vomiting. Anesthesia and analgesia. 2000; 91: 136-9.

24. Apfel CC, Philip BK, Cakmakkaya OS, Shilling A, Shi YY, Leslie JB, et al. Who is at risk for postdischarge nausea and vomiting after ambulatory surgery? Anesthesiology. 2012; 117: 475-86.

25. Kim SH, Shin YS, Oh YJ, Lee JR, Chung SC, Choi YS. Risk assessment of postoperative nausea and vomiting in the intravenous patient-controlled analgesia environment: predictive values of the Apfel's simplified risk score for identification of high-risk patients. Yonsei Med J. 2013; 54: 1273-81.

26. Waldron NH, Jones CA, Gan TJ, Allen TK, Habib AS. Impact of perioperative dexamethasone on postoperative analgesia and side-effects: systematic review and meta-analysis. British journal of anaesthesia. 2013; 110: 191-200.

27. Sapolsky RM, Romero LM, Munck AU. How do glucocorticoids influence stress responses? Integrating permissive, suppressive, stimulatory, and preparative actions. Endocrine reviews. 2000; 21: 55-89.

28. Kim HJ, Lee HC, Jung YS, Lee J, Min JJ, Hong DM, et al. Effect of palonosetron on the QTc interval in patients undergoing sevoflurane anaesthesia. British journal of anaesthesia. 2014; 112: 460-8.

29. Choi YS, Shim JK, Yoon DH, Jeon DH, Lee JY, Kwak YL. Effect of ramosetron on patient-controlled analgesia related nausea and vomiting after spine surgery in highly susceptible patients: comparison with ondansetron. Spine. 2008; 33: E602-6.

30. Kim SH, Oh CS, Lee SJ. Efficacy of palonosetron and ramosetron on postoperative nausea and vomiting related to intravenous patient-controlled analgesia with opioids after gynecological laparoscopic surgery (double-blinded prospective randomized controlled trial). Journal of anesthesia. 2015; 29: 585-92.

31. Murphy GS, Szokol JW, Greenberg SB, Avram MJ, Vender JS, Nisman M, et al. Preoperative dexamethasone enhances quality of recovery after laparoscopic cholecystectomy: effect on in-hospital and postdischarge recovery outcomes. Anesthesiology. 2011; 114: 882-90.

32. Choi KW, Nam KH, Lee JR, Chung WY, Kang SW, Joe YE, et al. The Effects of Intravenous Lidocaine Infusions on the Quality of Recovery and Chronic Pain After Robotic Thyroidectomy: A Randomized, Double-Blinded, Controlled Study. World J Surg. 2017; 41: 1305-12.

33. Brown ES. Effects of glucocorticoids on mood, memory, and the hippocampus. Treatment and preventive therapy. Annals of the New York Academy of Sciences. 2009; 1179: 41-55. 